\title{
Dinâmica das Exportações de Mel Natural Brasileiro no Período de 2000 a 2011
}

\author{
Maristela Franchetti Paula ${ }^{1}$, Anadalvo Juazeiro dos Santos ${ }^{1}$, \\ João Carlos Garzel Leodoro da Silva ${ }^{1}$, Romano Timofeiczyk Junior ${ }^{1}$, \\ Vitor Afonso Hoeflich ${ }^{2}$ \\ ${ }^{1}$ Universidade Federal do Paraná - UFPR, Curitiba/PR, Brasil \\ ${ }^{2}$ Departamento de Economia Rural e Extensão, Universidade Federal do Paraná - UFPR, Curitiba/PR, Brasil
}

\begin{abstract}
RESUMO
Este trabalho teve como objetivo descrever a dinâmica das exportações do mel natural brasileiro no período de 2000 a 2011. Para o desenvolvimento deste artigo foi realizado o levantamento bibliográfico sobre as exportações de mel natural utilizando fontes de consulta como: Sebrae, IBGE, sistema Aliceweb, dados do UNcomtrade. Também foi aplicada a metodologia Razão de concentração para definir o grau de concentração; para esse cálculo utilizou-se a participação dos quatro e oito maiores mercados internacionais brasileiros. Os resultados demonstraram que o Brasil saiu de um volume baixo de exportações para chegar no ano de 2011 ocupando o quinto lugar nas exportações mundiais, tendo como principais países de destino, nomeadamente, os Estados Unidos, Alemanha, Reino Unido, Canadá, Espanha e Bélgica. Estados Unidos e Alemanha participaram com mais de $80 \%$ do total exportado pelo país no período estudado, evidenciando uma alta concentração de mercado, comprovada pela metodologia aplicada.
\end{abstract}

Palavras-chave: concentração, Brasil, mercado internacional.

\section{Dynamics of the Brazilian Exports of Natural Honey Between 2000 and 2011}

\begin{abstract}
This study aimed to describe the dynamics of the Brazilian exports of natural honey in the 2000-2011 period. To this end, a literature survey on exports of natural honey was carried out at the following reference data sources: SEBRAE, IBGE, Aliceweb, and UNcomtrade. The concentration ratio (CR) methodology was also applied to define the degree of concentration; this calculation was based on the participation of the four and the eight largest Brazilian export markets. The results showed that Brazil evolved from a low volume of exports in 2000 to the $5^{\text {th }}$ place in world exports in 2011, exporting mainly to the United States, Germany, United Kingdom, Canada, Spain and Belgium. The United States and Germany participated with more than $80 \%$ of the total Brazilian exports of natural in the period studied, indicating a high market concentration proven by the methodology applied.
\end{abstract}

Keywords: concentration, Brazil, international market. 


\section{INTRODUÇÃO E OBJETIVOS}

Segundo Sommer (2002), a apicultura desempenha papel importante no quadro socioeconômico mundial. É uma das poucas atividades que atende aos requisitos do tripé da sustentabilidade: o econômico, o social e o ecológico. O econômico é o gerador de renda para os produtores; o social intensifica a ocupação de mão de obra familiar no campo, com diminuição do êxodo rural; e o ecológico refere-se à polinização de espécies nativas e cultivadas e à conservação da vegetação, já que não é necessário desmatar para criar abelhas, necessitando-se de plantas vivas para a retirada do pólen e do néctar de suas flores, fontes alimentares básicas das colméias.

O Brasil possui flora diversificada e clima favorável, que o credenciam como um dos maiores produtores de mel do mundo. Outro fator importante é o diferencial de que as abelhas africanizadas possuem resistência às pragas e doenças. Além disso, essa espécie apresenta um comportamento higiênico que impede a disseminação das enfermidades, dispensando o uso de medicamentos. Com essas características, o país oferece ao mercado um produto diferenciado pela sua qualidade e sabor (SEBRAE, 2006).

Praticamente todos os estados do país produzem mel natural, sendo os mais representativos: Rio Grande do Sul, Paraná, Santa Catarina, Piauí, Minas Gerais, Ceará, São Paulo e Bahia. No ano de 2000, conforme dados do IBGE (2013), a produção de mel no Brasil foi de aproximadamente 21,8 mil toneladas, em 2005 foi de 33,7 mil toneladas, em 2011, de 41,6 mil toneladas, constatando-se a evolução de $91 \%$ da produção no período de 2000 a 2011.

Apesar da evolução na produção de mel na última década, o Brasil ainda ocupa uma posição intermediária no contexto mundial. Segundo a FAO (2013), no ano de 2005, a produção total de mel no mundo chegou à marca de cerca de 1,4 milhão de toneladas, movimentando valores financeiros da ordem de 1,5 bilhão de dólares. No mundo, cerca de 130 países desenvolvem atividades apícolas, destacando-se na produção mundial China, (22,1\%), Estados Unidos (5,9\%), Argentina (5,8\%), Turquia (5,4\%), Ucrânia (4,4\%), México (4,1\%), Rússia $(3,8 \%)$ e Índia (3,8\%). Esse bloco de países produz 50\% do volume mundial de mel. O Brasil ocupa o $15^{\circ}$ lugar, respondendo por $1,8 \%$ da produção mundial.
Antes de 2000, o setor de mel no Brasil era voltado para o mercado interno e a produção era considerada baixa, sendo necessário importar para complementar as necessidades de consumo e produção industrial. Entre os anos de 2001 e 2004 ocorreu um choque na estrutura do mercado externo, provocado por barreiras às exportações do mel, impostas pelos principais países consumidores aos maiores exportadores. Nesse período, novos mercados afloraram, devido ao incremento de preços no mel natural, atraindo novos entrantes no comércio internacional, dentre os quais se destacou o Brasil (SEBRAE, 2006).

Nesse sentido, este artigo objetiva descrever a dinâmica das exportações do mel natural brasileiro no período de 2000 a 2011.

\section{MATERIAL E MÉTODOS}

Neste estudo foi aplicada metodologia para demonstrar a evolução das exportações no mercado de mel natural. Para definir o grau de concentração, foi analisado por meio do índice de razão de concentração, que é uma medida de concentração parcial, pois ela relaciona apenas as parcelas de mercados dos países líderes. Essa metodologia é utilizada para indicar a proporção das maiores firmas ou países em relação ao valor total exportado do setor correspondente as $\mathrm{k}$ maiores nações, considerando que estão ordenadas de forma decrescente (Hoffmann, 2006).

A equação matemática para calcular a razão de concentração (Equação 1) foi sugerida por Hoffmann (2006), e assim escreve-se:

$C R_{k}=\sum_{i=1}^{k} y i$

na qual: $C R_{k}=$ razão de concentração das $\mathrm{k}$ maiores nações; $y_{i}=$ market share em porcentagem da nação $i$ no mercado; $k=$ número de países.

Para Hoffmann (2006), a concentração de mercados é uma medida que consiste em indicar como é a estrutura do mercado, enquanto que, para Braga \& Mascolo (1982), a concentração significa acumulação de certos atributos econômicos (tais como renda, riqueza, produção, valor etc.) por correspondentes unidades de controle (indivíduos, firmas, estabelecimentos industriais, países). 
De acordo com Hoffmann (2006), o grau de concentração é tanto maior quanto menor for o número de empresas, ou seja, um alto grau de concentração ocorre quando uma grande proporção do valor total corresponde a um pequeno número de unidades. Para Kon (1994), alto índice de concentração prejudica a competição, pois as empresas são encorajadas a agir de forma interdependente no que se refere às decisões sobre preços, produção e assuntos correlatos.

Neste estudo avaliou-se a razão de concentração das exportações brasileiras $\mathrm{CR}_{4}$ (os quatro maiores importadores do mel natural) e $\mathrm{CR}_{8}$ (conjunto dos oito maiores importadores do mel natural), sendo que a identificação do grau de concentração das exportações foi realizada a partir da divisão de concentração de mercado realizada por Medeiros \& Reis (1999), apresentada no Quadro 1 a seguir.

$\mathrm{O}$ tamanho de k é que define a medida calculada. Assim se $\mathrm{k}=4$ tem-se que $\mathrm{CR}_{4}$ é a participação relativa dos quatro maiores mercados no total das exportações do Brasil; da mesma forma, se $\mathrm{k}=8$ tem-se $\mathrm{CR}_{8}$ representando a participação dos oito maiores mercados que serão estudados na razão da concentração. Quanto maior for o CR, maior é a concentração das exportações do produto estudado nos $\mathrm{k}$ maiores países.

A relação é de fácil interpretação, ou seja, se, por exemplo, um número pequeno de países é responsável por uma grande proporção da produção, das vendas etc. da indústria, então o nível de concentração é alto e existe uma maior probabilidade de se estar diante de práticas oligopolísticas que na ocorrência de uma baixa relação de CRk (Kon, 1994).

Essa uma medida de concentração é utilizada, principalmente, em estudos relacionados aos setores da agricultura e pecuária como, por exemplo, na cadeia alimentar da soja, no segmento agroindustrial da avicultura, entre outros (Parapinski, 2012).

Para o levantamento bibliográfico sobre as exportações de mel natural foram utilizadas diversas fontes de consulta como: Sebrae, IBGE, sistema Aliceweb do Ministério do Desenvolvimento, Indústria e Comércio Exterior. Também foram utilizados dados das séries temporais anuais no período de 2000-2011 do produto mel natural, contidas no site do Comércio Internacional das Nações Unidas - UNcomtrade. Esses dados dizem respeito a volume (t) e valor (US\$) das exportações brasileiras e mundiais do produto. Esses dados estão expressos em milhões de dólares e deflacionados para o ano de 2011 com base no índice dos Estados Unidos Consumer Price Index (CPI), por se tratar de comércio internacional.

\section{RESULTADOS E DISCUSSÕES}

Os principais exportadores de mel natural no mundo são: China, Argentina, México e Alemanha. As exportações mundiais de mel natural no período de 2000 a 2011 chegaram a aproximadamente 4,9 bilhões de toneladas. A China merece destaque por ser o maior exportador, com $21 \%$ do total, seguida da Argentina, com 19\%. Os outros países participam com um percentual menor, como o México, que é o terceiro, participando com $6 \%$, seguido do Canadá, Hungria e Brasil, com $4 \%$ do total exportado no período cada um. Os outros países produtores representam 32\% da exportação mundial, conforme Figura 1 a seguir.

Com relação ao valor exportado no mundo no período de 2000 a 2011, alcançou mais de US\$12,4 bilhões de dólares, sendo que a China participa com $12 \%$ e a Argentina com 15\%. Isso confirma que a China exporta

Quadro 1. Tipos de mercados segundo a razão de concentração.

Chart 1. Types of markets according to the concentration ratio.

\begin{tabular}{|lcc|}
\hline \multirow{2}{*}{ NÍVEIS DE MERCADO } & \multicolumn{2}{c|}{ RAZÕES DE CONCENTRAÇÃO } \\
\cline { 2 - 3 } & CR $_{4}$ & CR $_{\mathbf{8}}$ \\
\hline Altamente concentrado & $\mathrm{I}>75 \%$ & $\mathrm{I}>90 \%$ \\
Alta concentração & $65 \%<\mathrm{i}<75 \%$ & $85 \%<\mathrm{i}<90 \%$ \\
Concentração moderada & $50 \%<\mathrm{i}<65 \%$ & $70 \%<\mathrm{i}<85 \%$ \\
Baixa concentração & $35 \%<\mathrm{i}<50 \%$ & $45 \%<\mathrm{i}<70 \%$ \\
Ausência de concentração & $\mathrm{I}<35 \%$ & $\mathrm{I}<45 \%$ \\
Claramente atomístico & $\mathrm{I}=2 \%$ & \\
\hline
\end{tabular}

Fonte: Medeiros \& Reis (1999). 
um volume maior por um preço médio menor, que é de US\$1,49, e a Argentina apresenta um preço médio de US\$2,07, considerado mais elevado e próximo do preço médio dos maiores exportadores, no período estudado, que foi de US\$2,29. O México participa com $6 \%$, Alemanha, com 9\%, Hungria e Espanha, com 5\%, Canadá e Brasil, com $4 \%$ cada um.

Quando se considera o comércio internacional de mel, China e Argentina respondem por $40 \%$ das exportações mundiais. A China ocupa posição de destaque, com $21 \%$ do mel produzido, embora ofertando um produto com características de qualidade inferior e preços baixos (USAID, 2006). Apesar das medidas de antidumping aplicadas pelo mercado americano à Argentina e a imposição de barreiras sanitárias ao mel chinês pela União Europeia e Estados Unidos, entre 2001 e 2004 esses países continuaram a se destacar na produção de mel.

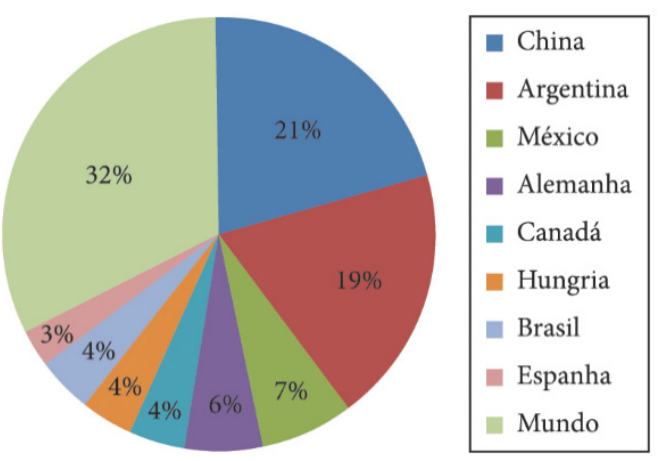

Figura 1. Países maiores exportadores mundiais de mel natural, período de 2000 a 2011. Fonte: UNcomtrade (2013).

Figure 1. Major world exporters of natural honey, period 2000-2011. Source: UNcomtrade (2013).
Com relação aos principais países importadores do mundo, a Tabela 1 demonstra os valores comercializados no período de 2000 a 2011, apresenta a quantidade, valor nominal e real, bem como o preço médio pago por esses países na compra do mel natural.

Como a produção de mel nos países desenvolvidos não consegue atender à demanda interna, esses países detentores de grandes mercados consumidores são os principais importadores mundiais: Estados Unidos e Alemanha respondem por pouco menos de 50\% do volume total, seguidos por Japão, Reino Unido, França, Espanha, Itália, Bélgica e Arábia Saudita, segundo UNcomtrade (2013).

O destaque da evolução das exportações do Brasil comparada a dos outros países exportadores se comprova a partir das taxas de crescimento, conforme Tabela 2 .

O Brasil exportou no período de 2000 a 2011 próximo a183 milhões de toneladas, no valor real de US\$ 452 milhões, com preço médio de US\$2,47 por quilo. Apresentou no período estudado uma taxa de crescimento de $648 \%$ em quilos e de $111 \%$ no preço médio, taxas consideradas positivas se comparadas às dos maiores exportadores do mundo.

A taxa de crescimento é atrativa, mas não acompanhou a taxa de crescimento do valor. Se comparada com as dos outros países, a maioria não teve aumento em sua taxa de crescimento com relação à quantidade, mas apresentou taxas positivas com relação ao preço médio, conforme demonstrado na Tabela 2 .

O Brasil atua no mercado internacional exportando para os principais países importadores do mundo. A Figura 2 evidencia esses países e sua participação no volume de exportações do mel brasileiro.

Tabela 1. Total das importações dos principais países consumidores mundiais de mel natural no período 2000 a 2011.

Table 1. Total imports of major countries worldwide consumers of natural honey in the period 2000-2011.

\begin{tabular}{lcccc}
\multicolumn{1}{c}{ PAÍs } & $\begin{array}{c}\text { QUANTIDADE } \\
\text { KG }\end{array}$ & $\begin{array}{c}\text { VALOR NOMINAL } \\
\text { (US\$) }\end{array}$ & $\begin{array}{c}\text { VALOR REAL } \\
\text { (US\$) }\end{array}$ & $\begin{array}{c}\text { PREÇO MÉDIO } \\
\text { (US\$) }\end{array}$ \\
\hline USA & 1.203 & 2.385 & 2.699 & 2,24 \\
\hline ALEMANHA & 1.090 & 2.436 & 2.785 & 2,56 \\
\hline JAPÃO & 496 & 840 & 956 & 1,93 \\
REINO UNIDO & 341 & 900 & 1.015 & 2,97 \\
\hline FRANÇA & 249 & 724 & 812 & 3,26 \\
ESPANHA & 177 & 340 & 386 & 2,19 \\
ITÁLIA & 166 & 431 & 489 & 2,95 \\
\hline BÉLGICA & 149 & 345 & 387 & 2,59 \\
\hline
\end{tabular}

Fonte: UNcomtrade (2013). 
Tabela 2. Taxa de crescimento dos maiores exportadores mundiais de mel natural no período de 2000 a 2011.

Table 2. Growth rate of world's largest exporters of natural honey in the period 2000-2011.

\begin{tabular}{lcc}
\multicolumn{1}{c}{ PAÍS } & $\begin{array}{c}\text { QUANTIDADE } \\
(\mathbf{k g})\end{array}$ & $\begin{array}{c}\text { PREÇO } \\
(\mathbf{k g})\end{array}$ \\
\hline Brasil & $648 \%$ & $111 \%$ \\
Espanha & $117 \%$ & $88 \%$ \\
\hline China & $-2 \%$ & $74 \%$ \\
\hline Hungria & $-2 \%$ & $152 \%$ \\
Alemanha & $-12 \%$ & $168 \%$ \\
\hline México & $-15 \%$ & $126 \%$ \\
\hline Argentina & $-35 \%$ & $142 \%$ \\
\hline Canadá & $-38 \%$ & $132 \%$ \\
\hline
\end{tabular}

Fonte: UNcomtrade (2013)

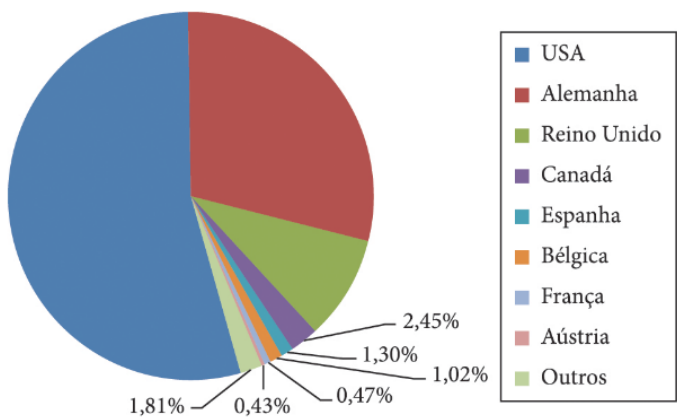

Figura 2. Principais mercados do mel brasileiro no período de 2000 a 2011. Fonte: UNcomtrade (2013).

Figure 2. Main markets of Brazilian honey in the period 2000-2011. Source: UNcomtrade (2013).
O Brasil é o sétimo maior exportador do mundo, considerando o período de 2000 a 2011, e alcançou o quinto lugar em exportações no ano de 2011. Exporta para países importantes para as exportações mundiais, com um alto e constante consumo de mel, como: Estados Unidos, Alemanha, Reino Unido e Japão.

Estados Unidos e Alemanha foram os maiores clientes do Brasil no período de 2000 a 2011, importando quase $80 \%$ do total exportado pelo Brasil. A Figura 2 mostra alta concentração, o que gera dependência e certa vulnerabilidade, pois esses países são rigorosos em seus critérios de qualidade e prazos de entrega e podem a qualquer tempo aplicar sansões ao mel brasileiro.

A Tabela 3 apresenta o total das exportações anuais, demonstrando sua quantidade, valor real e preço médio no período de 2000 a 2011.

Com relação ao preço médio do mel no mercado mundial, apresentado na Tabela 3, tomando por base as exportações brasileiras, observam-se oscilações, alcançando-se a média de US\$2,47/kg. O maior valor do preço médio foi em 2011, quando chegou a US\$3,23/kg. O preço médio em 2000 foi de US\$1,70/kg, em 2005 chegou a US\$1,54/kg, devido às restrições impostas pelo mercado europeu ao mel brasileiro. A Figura 3 demonstra a evolução do preço médio, demonstrando visualmente suas oscilações.

A oscilação de preço se deve, principalmente, à influência da China e da Argentina no mercado,

Tabela 3. Exportação do mel natural brasileiro no período de 2000 a 2011.

Table 3. Exports of Brazilian natural honey in the period 2000-2011.

\begin{tabular}{cccc|}
\hline ANO & $\begin{array}{r}\text { QUANTIDADE } \\
\text { (MIL KG) }\end{array}$ & $\begin{array}{c}\text { VALOR REAL } \\
\text { ( MIL US\$) }\end{array}$ & $\begin{array}{c}\text { PREÇO MÉDIO } \\
\text { (KG/US\$) }\end{array}$ \\
\hline 2000 & 269.103 & 456 & 1,70 \\
2001 & 2.489 .214 & 3.665 & 1,47 \\
\hline 2002 & 12.643 .362 & 29.574 & 2,34 \\
\hline 2003 & 19.273 .750 & 56.861 & 2,95 \\
\hline 2004 & 21.037 .120 & 51.517 & 2,45 \\
\hline 2005 & 14.447 .958 & 22.304 & 1,54 \\
\hline 2006 & 14.601 .908 & 26.618 & 1,82 \\
\hline 2007 & 12.907 .267 & 23.469 & 1,82 \\
\hline 2008 & 18.271 .297 & 46.463 & 2,54 \\
\hline 2009 & 25.987 .195 & 70.409 & 2,71 \\
\hline 2010 & 18.629 .061 & 57.933 & 3,11 \\
\hline 2011 & 22.398 .577 & 72.335 & 3,23 \\
\hline
\end{tabular}

Fonte: UNcomtrade (2013). 
principais exportadores mundiais. Importante destacar que embora o preço médio demonstre oscilações, em nenhum momento ele esteve abaixo do valor histórico do produto no mercado externo (US\$1,30), nem tampouco ficou abaixo do custo de produção (US\$ 0,68), conforme dados do relatório da Agência dos Estados Unidos para o Desenvolvimento Internancional (USAID, 2006).

A Figura 4 apresenta visualmente as exportações brasileiras no que se refere a quantidade e valor, no período de 2000 a 2011.

A figura anterior mostra que o volume exportado pelo Brasil em 2000 era de 269 toneladas; a partir da entrada no mercado internacional em 2001 seu aumento foi expressivo, chegando em 2011 com 22,4 mil toneladas. A Figura 4 demonstra o crescimento rápido no volume de exportações a partir de 2001 até 2004. Quando do retorno da Argentina e China ao mercado internacional, em 2004, o preço médio foi drasticamente influenciado, como mostra a figura. O quadro foi agravado entre os anos de 2006 a 2008, quando a União Europeia embargou o mel brasileiro por não serem atendidas as medidas de redução de resíduos impostas por essa comunidade ao setor

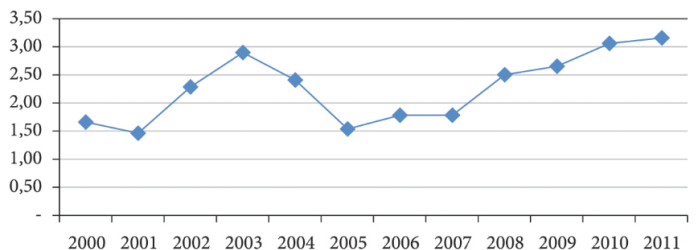

Figura 3. Evolução do preço médio do mel brasileiro no período de 2000 a 2011. Fonte: UNcomtrade (2013). Figure 3. Evolution of average price of Brazilian honey in the period 2000-2011. Source: UNcomtrade (2013). apícola brasileiro. As exportações foram direcionadas para os Estados Unidos, atenuando os impactos das restrições impostas.

Outro fator que merece ser destacado são os índices de concentração dos principais exportadores mundiais, tendo como resultado a verificação de um processo de concentração no mercado de mel natural. Para obter os resultados, utilizou-se do índice CRk, que mensura a razão de concentração em diferentes mercados, duas aferições para medir o grau de concentração, levando-se em conta os oito e os quatro maiores países exportadores.

A partir dos resultados revelados por CR4 e CR8 foi possível perceber a alta concentração do mercado mundial. Os níveis de concentração para os quatro e oito maiores mercados para a exportação de mel natural são apresentados na Tabela 4 .

Analisando-se a Tabela 4 percebe-se que a maioria dos países são altamente concentrados, como o Brasil, que concentra $80 \%$ das suas exportações em dois países, Estados Unidos e Alemanha. As exceções são a Argentina e a Alemanha, que possuem mercados com moderada e baixa concentração.

A Argentina possui um mercado com um número maior de países importadores. Exportou quase 50\% do total do período de 2000 a 2011 para Alemanha e Estados Unidos, em seguida os países que mais receberam mel argentino foram Reino Unido, Japão e França, os outros países somados representam quase $25 \%$ do total das exportações.

Somente a Alemanha possui baixa concentração, pois apresenta características específicas. O país é

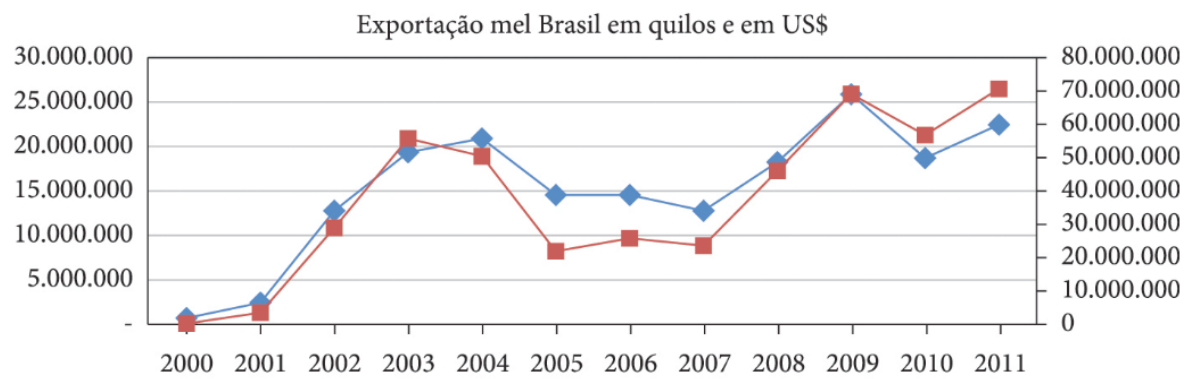

$-\mathrm{kg}-\mathrm{ES} \$$

Figura 4. Evolução das exportações do mel brasileiro (kg e valor US\$) no período de 2000 a 2011 . Fonte: UNcomtrade (2013).

Figure 4. Evolution of exports of Brazilian honey (kg and U.S. \$ value) in the period 2000-2011. Source: UNcomtrade (2013). 
Tabela 4. Razão de concentração dos maiores exportadores mundiais de mel de 2000 a 2011.

Table 4. Ratio of concentration of the largest exporters of honey from 2000 to 2011.

\begin{tabular}{llccc}
\multicolumn{1}{c}{ País } & CR 4 & Nível de mercado & CR 8 & Nível de mercado \\
\hline Canadá & $94,89 \%$ & Altamente concentrada & $98,00 \%$ & Altamente concentrada \\
Brasil & $94,80 \%$ & Altamente concentrada & $98,17 \%$ & Altamente concentrada \\
México & $85,67 \%$ & Altamente concentrada & $97,32 \%$ & Altamente concentrada \\
Hungria & $79,85 \%$ & Altamente concentrada & $98,10 \%$ & Altamente concentrada \\
China & $72,04 \%$ & Alta concentração & $83,41 \%$ & Concentração moderada \\
Espanha & $65,98 \%$ & Alta concentração & $81,51 \%$ & Concentração moderada \\
Argentina & $58,66 \%$ & Concentração moderada & $67,92 \%$ & Baixa concentração \\
\hline Alemanha & $49,21 \%$ & Baixa concentração & $70,01 \%$ & Baixa concentração \\
\hline
\end{tabular}

CR 4 = Razão de concentração dos 4 países mais exportadores; CR 8 = Razão de concentração dos 8 países mais exportadores.

considerado um dos maiores importadores e exportadores do mundo, exportando principalmente para o Reino Unido e França, que representam quase 15\% do total exportado no período de 2000 a 2011. Em seguida, os maiores importadores são Itália, Bélgica, Espanha e Holanda, que representam 12\% do total exportado no período estudado. Os países com menores volumes de exportações representam 75\% do total exportado no período, mostrando-se um mercado com baixa concentração. A Alemanha fraciona, agrega valor ao produto e exporta, principalmente para a Europa, sendo considerado o principal distribuidor do produto nesse bloco econômico.

O mercado exterior do mel natural, no período de 2000 a 2001, caracterizou-se pelo aumento da demanda, crescimento das exportações e, principalmente, porque novos países exportadores se destacaram quando dos embargos e restrições impostos a China e Argentina, dentre eles o Brasil. Outra característica relevante desse mercado é a concentração, já que China e Argentina são responsaveis por $40 \%$ das exportações mundiais, e, dentre os importadores, Estados Unidos e Alemanha respondem por mais de $80 \%$ do total exportado no mundo.

Importante comentar que, devido a alta concentração de mercado, as principais fontes de choques no mercado mundial de mel residem em possíveis barreiras e sanções comerciais impostas pelos principais países importadores, Alemanha e Estados Unidos, que também são produtores de mel, como aconteceu em 2001 em relação à China e à Argentina e, mais recentemente, ao Brasil, em março de 2006. Apesar do embargo da União Europeia ao Brasil ter como objetivo forçar as autoridades a instituírem um maior controle de resíduos na produção brasileira, influenciou as exportações e preços no período da restrição.

Essas medidas restritivas alteram expressivamente o mercado externo de diversos países e devem ser consideradas como uma ameaça constante a todos os novos players que ainda não adequaram sua produção às exigências dos mercados importadores (ABEMEL, 2013).

\section{CONCLUSÕES}

O mercado internacional de mel natural aparentemente pode não ter importância econômica, mas é uma oportunidade para países como o Brasil. Esse mercado apresentou nos últimos anos demanda crescente e constante, tendo como consequência o crescimento das exportações e importações.

O Brasil apresenta destaque no mercado mundial, comprovado pela evolução na sua participação, com taxas de crescimento expressivas e constantes. Demonstrando sua capacidade em ocupar uma das primeiras posições do ranking dos maiores exportadores do mundo, com um produto de qualidade e sem contaminações. Tendo como consequências positivas as contribuições sociais, ambientais e econômicas para produtores rurais, principalmente aqueles que têm na apicultura uma fonte de renda complementar.

\section{STATUS DA SUBMISSÃO}

Recebido: 15 out., 2013

Aceito: 21 mar., 2015 


\section{AUTOR(ES) PARA CORRESPONDÊNCIA}

\section{Maristela Franchetti Paula}

Universidade Federal do Paraná - UFPR, Av. Lothário Meissner, 900, Jardim Botânico, CEP 80210-170, Curitiba, PR, Brasil e-mail:mc1503@yahoo.com.br

\section{REFERENNCIAS}

Agência dos Estados Unidos para o Desenvolvimento Internacional - USAID. Análise da indústria de mel: inserção de micro e pequenas empresas no mercado internacional. Brasília; 2006. v. 2.

Associação Brasileira dos Exportadores de Mel - ABEMEL. Rio Claro. [cited 2013 June]. Available from: http:// abemel.com.br/portal.

Braga H, Mascolo J. Mensuração da concentração industrial no Brasil. Pesquisa e Planejamento Economico 1982; 12(2): 399-454.

Food and Agriculture Organization - FAO. Statistical databases. Rome. [cited 2013 June]. Available from: www.fao.org.
Hoffmann R. Estatística para economistas. São Paulo: Pioneira; 2006. Biblioteca Pioneira de Ciências Sociais.

Instituto Brasileiro de Geografico e Estatística - IBGE. Sistema IBGE de Recuperação Automatica - SIDRA. Brasília. [cited 2013 June]. Available from: http://www. sidra.ibge.gov.br/bda/tabela/listabl.asp? $\mathrm{c}=74 \& \mathrm{z}=\mathrm{p} \& \mathrm{o}=25$.

Kon A. Economia industrial. São Paulo: Nobel; 1994.

Medeiros NH, Reis SV. A concentração industrial na cadeia alimentar da soja. In: Anais do XXXVII Congresso Brasileiro da Sober; 1999; Foz do Iguaçu. Brasília: SOBER; 1999. p. 1-15.

Parapinski ML. Desempenho das exportações brasileiras de móveis de madeira, 1991 a 2010 [dissertação]. Curitiba: Programa de Pós-Graduação em Engenharia Florestal, Universidade Federal do Paraná; 2012.

Serviço Brasileiro de Apoio às Micro e Pequenas Empresas - SEBRAE. Desafios da apicultura brasileira. Revista SEBRAE Agronegócios 2006; 3: 1-64.

Sommer PG. Panorama da apicultura mundial. In: Anais Congresso Brasileiro de Apicultura; 2002; Campo Grande, MS. Campo Grande: CBA: UFMS: FAAMS; 2002.

United Nations Commodity Trade Statistics Database UNcomtrade. [cited 2013 June]. Available from: http:// comtrade.un.org/db/default.aspx. 